\title{
Influence of Twin-Screw Processing Conditions on Structure and Properties of \\ Polypropylene - Organoclay Nanocomposites
}

\author{
T. Domenech, E. Peuvrel-Disdier, B. Vergnes \\ MINES ParisTech, CEMEF (Centre de Mise en Forme des Matériaux), \\ UMR CNRS 7635, BP 207, 06904 Sophia Antipolis (France)
}

Correspondence to: Bruno Vergnes; e-mail: bruno.vergnes@mines-paristech.fr

Key words: Nanocomposite, twin screw extrusion, processing conditions, specific mechanical energy 


\begin{abstract}
This study looks at the influence of extrusion parameters such as screw speed, feed rate and barrel temperature on the nanocomposite structure (size of agglomerates, level of intercalation and exfoliation) and its consequences on final mechanical properties. Nanocomposites of polypropylene, maleated polypropylene and organomodified montmorillonite, with respective mass fractions of $85 / 10 / 5$, were prepared in a co-rotating twin-screw extruder using a masterbatch dilution method. The nanocomposites structure was quantified by scanning and transmission electron microscopy, X-ray diffraction and dynamic rheometry. Relationships between the microstructure at different levels (size and number of agglomerates, interlayer distance, melt yield stress to quantify the exfoliation level) and the processing conditions were established, revealing that specific mechanical energy received during extrusion was the key parameter controlling this microstructure. Mechanical properties in uniaxial tension (apparent Young's modulus) were measured and related to the microstructural parameters resulting from extrusion conditions.
\end{abstract}




\section{Introduction}

Polymer/layered silicate nanocomposites have triggered a huge interest from both academic and industrial point of view since their properties and potential applications have been highlighted by Toyota researchers in the early 90’s (Fukushima and Inagaki, 1987; Usuki et al., 1993; Okada and Usuki, 1995). Indeed, these materials revealed improvement in mechanical and gas barrier properties, fire retardant behaviour and dimensional stability compared to the neat polymer matrix (Giannelis, 1996; Cho and Paul, 2001; Kim et al., 2007). Furthermore, properties improvement generally occurs at low filler concentration (between 1 and $10 \mathrm{wt} \%$ ) and is linked to the fine structure of dispersed/distributed clay layers within the polymer matrix, featuring high aspect ratio and specific surface of the organic filler. Formation of such hybrid materials can either be achieved by in situ polymerization or melt mixing process, melt mixing being more adapted to industrial scale production for cost and processability reasons. In the case of polyolefin matrix like polypropylene, low affinity between non-polar polymer chains and polar silicate surface is an obstacle to the formation of an exfoliated structure, as opposed to polymer containing polar functions like polyamide. Addition of a compatibilizer like polypropylene grafted with maleic anhydride and treatment of the layered silicate by organic surfactants has shown promising ability to overcome this affinity issue (Kato et al., 1997; Lertwimolnun and Vergnes, 2005; Kim et al., 2007). Nevertheless, reaching a good state of dispersion remains difficult and requires optimal processing conditions. Surprisingly, only a few studies about the impact of processing conditions on nanocomposites structure can be found in the literature (Cho and Paul, 2001; Dennis et al., 2001; Shah and Paul, 2004; Lertwimolnun and Vergnes, 2005, 2006, 2007; Vergnes and Lertwimolnun, 2008; Méderic et al., 2006, 2009). In the present paper, we propose to investigate how the processing parameters of a twin screw extrusion process are related to the final structure and the mechanical properties of polypropylene/organoclay nanocomposites. 


\section{Materials and methods}

\subsection{Materials}

Injection grade isotactic polypropylene (PP) homopolymer was purchased from LyondellBasell Polyolefins. This grade (Moplen ${ }^{\odot}$ HP400R) had a 25 g/10 min melt flow index $\left(230^{\circ} \mathrm{C}, 2.16 \mathrm{~kg}\right)$ and a density of $0.905 \mathrm{~g} / \mathrm{cm}^{3}$. Its molecular weight distribution was determined by size exclusion chromatography, giving number average molecular mass $M_{n}=58500 \mathrm{~g} / \mathrm{mol}$ and polydispersity index $I_{p}=3.5$. Montmorillonite based organoclay (OMMT) was kindly supplied by Laviosa Chimica Mineraria (Livorno, Italy). This grade of clay (Dellite ${ }^{\odot}$ 67G) featured dimethyldehydrogenated-tallow quaternary ammonium as organic modifier with 48 wt $\%$ of organic modifier content and CEC (cation exchange capacity) of 115 meq/100 g. Specific weight of the organoclay powder was $1.7 \mathrm{~g} / \mathrm{cm}^{3}$. Polypropylene grafted with maleic anhydride (PP-g-MA) was purchased from Eastman and used as a compatibilizer. This PP-g-MA grade (Eastman G3015) had a MA content of $3.1 \mathrm{wt} \%$ and a density of $0.913 \mathrm{~g} / \mathrm{cm}^{3}$. Its number average molecular mass $M_{n}$ was $24800 \mathrm{~g} / \mathrm{mol}$ and its polydispersity index $I_{p}$ was 1.9 .

\subsection{Nanocomposite preparation}

Nanocomposites were prepared by twin screw extrusion using a masterbatch dilution method. The masterbatch was compounded by the Danish Technological Institute (DTI, Taastrup, Denmark). It contained 40 wt $\%$ of PP, 40 wt $\%$ of PP-g-MA and $20 w t \%$ of OMMT, i.e. a compatibilizer to organoclay ratio of 2:1.

The second step of the preparation consisted in diluting this masterbatch into PP to obtain a final PP/PP-g-MA/OMMT formulation of 85/10/5 wt\%. This processing step was achieved on a Rheomex PTW24 corotating twin screw extruder (Thermo Fisher, Massachusetts, USA). The screw profile used on this laboratory scale extruder $(D=24 \mathrm{~mm}, L / D=40)$ is shown in Fig. 1. The temperature was set at the same value for all barrel elements, except for the first one which 
was regulated at $80^{\circ} \mathrm{C}$. A mixture of PP and masterbatch pellets was previously tumbled mixed and then fed in barrel 1 by a gravimetric feeder (DDW-MD3-DDSR20-10, Brabender, Duisburg, Germany). Extruded strands were cooled down through a water bath and pelletized using a Thermo Fisher PRISM Varicut pelletizer.

Processing parameters were varied in terms of screw speed $N$, feed rate $Q$ and barrel temperature $T_{b}$. A first set of trials was performed with constant barrel temperature $\left(T_{b}=180^{\circ} \mathrm{C}\right)$ and feed rate $(Q=3 \mathrm{~kg} / \mathrm{h})$, for several screw speeds of 100, 300, 500, 700 and $900 \mathrm{rpm}$. Influence of the feed rate was then investigated, running the extruder with constant barrel temperature $\left(T_{b}=180^{\circ} \mathrm{C}\right)$ and screw speed $(N=500 \mathrm{rpm})$, for various feed rate values of 3,6 , 10, 15 and $20 \mathrm{~kg} / \mathrm{h}$. Finally, for constant screw speed $(N=500 \mathrm{rpm})$ and feed rate $(Q=3 \mathrm{~kg} / \mathrm{h})$, the barrel temperature was varied from 180 to 200 and $220^{\circ} \mathrm{C}$. For each processing condition, melt temperature at the die exit was measured by introducing a thermocouple into the bulk extrudate. Minimum residence time $t_{\min }$ was also evaluated by adding one coloured pellet into the hopper. Screw torque $C$ was recorded during extrusion, enabling the calculation of specific mechanical energy (SME) using the following equation:

$$
S M E=\frac{\alpha \cdot C \cdot N}{Q}
$$

where $\alpha$ is a constant depending on motor power, maximum screw speed and maximum torque.

\subsection{Morphology characterization}

Dispersion of layered silicate within polymer matrix via melt mixing can lead to a wide size distribution of the clay filler, from microscale clay agglomerates to nanoscale exfoliated single platelets. A systematic characterization of organoclay dispersion was thus performed on both microscopic and nanoscopic scale, for the various processing conditions. Agglomerate size distributions were determined by scanning electron microscopy (SEM), using a Philips XL30 
with accelerating voltage of $15 \mathrm{kV}$. Back-scattered electron detector was used to obtain phase contrast between clay filler and polymer matrix. Prior to SEM observations, sample surfaces were polished to obtain flat surfaces with roughness parameter $R_{a}$ close to $1 \mu \mathrm{m}$ and then sputter coated with $\mathrm{Au} / \mathrm{Pd}$ target (deposit thickness around $10 \mathrm{~nm}$ ). Quantitative size characterisation of clay agglomerates was carried out using image analysis (Visilog 5.0 software). Each area occupied by clay agglomerates on the observed surface was measured from the SEM pictures. Microscale clay dispersion was then quantified using two parameters:

- $A_{r}$, the area ratio, is the ratio between the total area filled by clay agglomerates $\sum A_{\text {clay }}$ and the analysed area $A_{0}$ :

$$
A_{r}=\frac{\sum A_{\text {clay }}}{A_{0}}
$$

- $N_{s}$, the agglomerate surface density, is the number of agglomerates per surface unit.

The analysed area $A_{0}$ was $17.2 \mathrm{~mm}^{2}$ and clay agglomerates with equivalent diameter inferior to $10 \mu \mathrm{m}$ were not taken into account in these microscale quantifications.

High magnification observations were made using transmission electron microscopy (TEM). with a Philips CM12 operating at $120 \mathrm{kV}$ acceleration tension and using a $\mathrm{LaB}_{6}$ cathode. Ultrathin sections were prepared from the central zone of an injection moulded tensile bar (in the plan normal to the flow direction) using an ultracryomicrotome (Ultracut, Leica Microsystems, Wetzlar, Germany) equipped with Cryotrim and 2 mm Cryo diamond knives (Diatome, Biel, Switzerland). Glass transition temperature of both PP and PP-g-MA being around $-10^{\circ} \mathrm{C}$, ultrathin sections were cut at $-100^{\circ} \mathrm{C}$ with a thickness of $50 \mathrm{~nm}$ and then collected on a copper grid.

\subsection{X-Ray diffraction (XRD) analysis}

OMMT layered structure gives rise to X-ray diffraction peaks corresponding to its interplanar distances, particularly the basal spacing $d_{001}$ which is the addition of one single platelet 
thickness $(0.96 \mathrm{~nm})$ with the interlayer distance. Intercalation of polymer chains between the clay galleries leads to an increased basal spacing (Vaia et al., 1993, 1995). As a consequence, Xray diffraction is often used to estimate the level of intercalation. Nanocomposites corresponding to each processing conditions were scanned using a X-ray diffractometer (Philips Xpert' Pro) with $\mathrm{Cu} \mathrm{K}_{\alpha}$ radiation $(\lambda=1.5405 \AA)$. The original organoclay powder was also analysed.

\subsection{Rheological analysis}

Small amplitude oscillatory shear measurements were performed on a controlled strain rheometer (ARES, TA Instruments, Delaware, USA). Parallel plate geometry with 25 mm diameter and $1 \mathrm{~mm}$ gap was used. All rheological tests were conducted in the molten state with a fixed temperature of $180^{\circ} \mathrm{C}$ under nitrogen environment. For each processing condition, a strain amplitude sweep test was run up to $300 \%$ at a constant angular frequency of $1 \mathrm{rad} / \mathrm{s}$ to determine the linear viscoelastic domain. Both time and frequency sweep tests were then carried out at a fixed strain within the linear viscoelastic range, following a procedure described in section 3.2. All rheological measurements were performed on disc-shaped samples prepared by compression molding using a hot press (Carver $\mathrm{M}$ 3853-0, Carver, Indiana, USA) at $180^{\circ} \mathrm{C}$ under $25 \mathrm{MPa}$ for $8 \mathrm{~min}$. An aluminium frame with circular cavities of $25 \mathrm{~mm}$ diameter and 1.5 mm thickness was used as a mould. A new sample was used for each rheological test.

\subsection{Mechanical properties}

Tensile tests were performed on an Erichsen tensile testing machine, at room temperature, on injected samples. The crosshead speed was fixed at $0.51 \mathrm{~cm} / \mathrm{min}$. Ten samples were characterized for each processing condition in order to check the reproducibility. Apparent Young's modulus and engineering strain at break were deduced from engineering stress-strain curves. Standard tensile specimens (ISO 525-2 1BA) were prepared using a Thermo Fisher 
MiniJet II small scale injection molding device. Barrel and mold temperatures were 200 and $70^{\circ} \mathrm{C}$, respectively. The injection pressure was set at 800 bar during $10 \mathrm{~s}$ and a holding pressure of 400 bar was applied for $10 \mathrm{~s}$. The collected tensile specimens were stored in a dessicator during several days prior to mechanical testing.

\section{Results and discussion}

OMMT have a wide size range. The smallest particle corresponds to an exfoliated individual platelet of approximately $1 \mathrm{~nm}$ thick and a few hundreds $\mathrm{nm}$ in lateral dimensions. These platelets are naturally associated in stacks, containing a few tens of sheets, commonly referred to as tactoids. OMMT are generally available as powder composed of agglomerates with characteristic size superior to $10 \mu \mathrm{m}$ (Fig. 2). These agglomerates are themselves composed of aggregated tactoids. Incorporation of OMMT into a molten polymer matrix during melt mixing process, such as twin screw extrusion, will first lead to powder grain agglomeration that must then be broken down along the screw profile, the dispersion efficiency being related to the processing conditions.

\subsection{Influence of screw speed on nanocomposite structure}

Dispersion of agglomerates during extrusion depends on the shear intensity, thus on the screw speed $N$. The dependence of clay agglomerate morphology with screw speed is presented in Fig. 3. Black zones are clay agglomerates and grey background is the PP/PP-g-MA matrix. These pictures reveal the presence of agglomerates with equivalent diameter between 10 and $180 \mu \mathrm{m}$, depending on screw speed. It can be noted that the original OMMT powder agglomerate size was within the range 10-40 $\mu \mathrm{m}$, as shown in Fig. 2. It means that further agglomeration of the powder occurred during the production of the masterbatch, probably due to its high concentration in OMMT (20 wt\%). However, it is clear that increasing screw speed led to a significant reduction of the largest agglomerate size. Indeed, Fig. 4 shows that both area ratio 
and agglomerate surface density drastically decreased when screw speed was increased, principally between 100 and $500 \mathrm{rpm}$.

Higher magnification micrographs obtained by TEM are presented in Fig. 5. The presence of both clay tactoids and exfoliated sheets can be observed. Transition from 100 to 500 rpm reveals a decrease in tactoids thickness (from 100 to $20 \mathrm{~nm}$ in average), leading to reduced distances between clay particles. On the other hand, the increase in screw speed from 500 to $900 \mathrm{rpm}$ did not induce large variations of the nanostructure.

XRD analysis showed that diffraction peaks related to the OMMT basal spacing remained visible whatever the screw speed. This means that the exfoliation was only partial, which was already clear from TEM observations (Fig. 5). A slight increase in basal spacing was observed for the nanocomposite processed at $100 \mathrm{rpm}$ compared to the Dellite ${ }^{\odot} 67 \mathrm{G}$ powder (from 3.45 to $3.60 \mathrm{~nm}$ ), indicating a possible intercalation. However, higher screw speed values led to a small decrease in the original basal spacing, that can be due to the degradation of the OMMT interlayer surfactant which is known to provoke interlayer spacing reduction (Méderic et al., 2006). This possible surfactant degradation could be attributed to the increase in melt temperature, induced by the increase of viscous dissipation with screw speed: final temperature increased from 191 to $253^{\circ} \mathrm{C}$ between 100 and $900 \mathrm{rpm}$.

The rheological behaviour of the nanocomposites in the melt state is sensitive to the structure, especially in the linear viscoelastic domain. As processing conditions play an important role on this structure, it is important to determine the linear domain for each processing conditions. Fig. 6 shows the results of dynamic strain sweep tests performed on the nanocom-posites processed for various screw speeds, as well as on the PP/PP-g-MA matrix. Important reduction of the linear domain was observed for the nanocomposites compared to the matrix, as expected for such filled materials (Cassagnau, 2008). It can also be noted that the reinforcement effect of the clay, resulting in an increase of the plateau modulus as well as a decrease in the linear domain, 
was more pronounced when the screw speed was increased. These results are linked to the improvement of the dispersion state obtained by the increase of screw speed. As a consequence, all rheological tests were performed with a fixed strain of $1 \%$ in order to be within the linear viscoelastic domain. It was also important to check the evolution of the rheological parameters with time. Dynamic time sweep test results for a period of 7200 seconds have shown that, unlike the matrix whose storage modulus is almost constant over this time period, nanocomposites exhibited a continuous increase of their storage modulus with time. This increase in storage modulus was more pronounced during the first 2000 seconds. This phenomenon was already reported for clay suspensions (Toorman, 1997; Pignon et al., 1998; Mobuchon et al., 2007) as well as for other polymer based layered silicate nanocomposites (Galgali et al., 2001; Li et al., 2003; Ren et al., 2003; Zouari et al., 2011). This particular behaviour reflects the evolution of clay-clay interactions due to the motion/disorientation of anisotropic fine clay particles (Treece and Oberhauser, 2007). Consequently, to perform consistent rheological measurements, each nanocomposite sample was kept under quiescent conditions within the rheometer at $180^{\circ} \mathrm{C}$ for 1800 seconds prior to frequency sweep tests, in order to "stabilize" the rheological behaviour (this type of protocol was previously used by some authors (Solomon et al., 2001; Lertwimolnun and Vergnes, 2005, 2006)). Results of the frequency sweep tests are plotted in Fig. 7. Addition of clay into the polymer matrix leads to a transition from a liquid-like (matrix) to a solid-like behaviour (nanocomposites) in the terminal zone (low pulsations), with the onset of a $G$ ' plateau and an increase in complex viscosity. Such rheological behaviour is characteristic of a percolated network formed by finely dispersed clay tactoids and exfoliated sheets (Solomon et al., 2001; Krishnamoorti and Yurekli, 2001). A model of Carreau-Yasuda with the addition of a yield stress term perfectly describes the complex viscosity dependence with the frequency (Vergnes, 2011): 


$$
\eta^{*}(\omega)=\frac{\sigma_{0}}{\omega}+\eta_{0}\left[1+(\lambda \omega)^{a}\right]^{\frac{n-1}{a}}
$$

where $\eta_{0}$ is the complex viscosity, $\omega$ the pulsation, $\sigma_{0}$ the melt yield stress, $\eta_{0}$ the zero-shear viscosity, $\lambda$ a characteristic time, $a$ the Yasuda parameter and $n$ the power law index. Rheological data were fitted using this model. Fig. 7b shows both data (symbols) and theoretical fit (solid lines). Increasing the extent of exfoliation leads to higher G' plateau and complex viscosity values at low pulsations (under $1 \mathrm{rad} / \mathrm{s}$ ) due to stronger clay-clay interactions, resulting in higher values of melt yield stress $\sigma_{0}$. It is thus possible to use $\sigma_{0}$ as a quantitative parameter of the exfoliation level. It can be seen in Fig. 8 that $\sigma_{0}$ depends on the screw speed. This effect of screw speed on exfoliation has been previously shown by other authors (Cho and Paul, 2001; Incarnato et al., 2003; Modesti et al., 2005, 2006; Lertwimolnun and Vergnes, 2005, 2006; Peltola et al., 2006). Up to $N=500 \mathrm{rpm}$, it increases linearly with $N$ and then saturates to a limit. It would mean that the increase in screw speed no longer contributes to the exfoliation of the organoclay above a certain point, at least as seen from a macroscopic point of view by rheometry. TEM micrographs shown in Fig. 5 also suggest, in a more qualitative way, that the nanostructure does not change much above $N=500 \mathrm{rpm}$.

\subsection{Influence of feed rate on nanocomposite structure}

Even though screw configuration or screw speed can affect the residence time distribution, it is generally much more sensitive to feed rate value (Poulesquen and Vergnes, 2003). As possible erosion of the clay sheets would be sensitive to the residence time, it was important to look at the impact of feed rate on the final nanocomposites structure.

SEM observations are presented in Fig. 9 whereas quantitative analysis results are plotted in Fig. 10. When feed rate was increased, thus when residence time was decreased, it is quite obvious that the OMMT dispersion quality was reduced, leading to the presence of larger agglomerates and also to a higher number of agglomerates. The same remark can be made about the 
aggregates, considering TEM acquisitions presented in Fig. 11. The thickness of the clay tactoids also increased when feed rate was increased. The minimum residence times $t_{\min }$ were measured as 130, 42, 31, 24 and 20 seconds, for feed rates of 3, 6, 10, 15 and $20 \mathrm{~kg} / \mathrm{h}$, respectively. This clearly shows that, at a fixed screw speed, the state of dispersion is sensitive to extrusion residence time, as reported by Dennis et al. (2001), Fasulo et al. (2004) or Lertwimolnun and Vergnes (2006).

XRD measurements showed that the interlayer distance increased from 3.3 to $3.6 \mathrm{~nm}$ when the feed rate was increased. In all cases, we observed an intercalated structure, partially exfoliated, and more intercalated when the residence time was short. Once again, the decrease of interlayer distance at long times could be related to a possible degradation of the intercalant at the extrusion temperature (here, around $210^{\circ} \mathrm{C}$ whatever the feed rate). Such an effect of feed rate on intercalation was already observed by Lertwimolnun and Vergnes (2007).

Results of the rheological dynamic frequency sweep tests are plotted in Fig. 12. Once again, the rheological behaviour of the nanocomposites differs from that of the PP/PP-g-MA matrix, especially at low pulsations. Solid lines in Fig. 12 represent the fit obtained using Eq. (3). Melt yield stress values are plotted as a function of feed rate in Fig. 13, exhibiting a decreasing dependency of power law type. The exfoliation level is therefore favoured by low values of feed rate, which is consistent with the observations performed by TEM. At both microscale and nanoscale, the OMMT dispersion quality is thus optimal for low feed rate values, i.e. long residence times. This result might be related to the kinetics of the OMMT dispersion process within polymer matrix, where diffusion of polymer chains within the clay galleries and erosion of clay sheets from the surface of agglomerates are often evoked in the literature (Vaia et al., 1993, 1995; Dennis et al., 2001). Similar trends of the melt yield stress dependence with mixing time were reported by Lertwimolnun and Vergnes (2005) using an internal mixer where the mixing time can be easily controlled. 


\subsection{Influence of barrel temperature on nanocomposite structure}

When the barrel temperature was increased, area ratio and surfacic density of agglomerates tend to increase slightly (from 1 to $1.3 \%$ and from 14 to $24 \mathrm{~mm}^{-1}$, respectively). XRD measurements clearly showed diffraction peaks, indicating a remaining intercalated structure. The interlayer distance was higher than the one of the OMMT, except at $240^{\circ} \mathrm{C}$, where a degradation of the intercalant was assumed.

Rheological measurements indicated a decrease of the melt yield stress with the barrel temperature (Fig. 14). However, the effect is less important than for variations of screw speed or feed rate. To summarize, the increase in barrel temperature led to a lower dispersion quality at both microscopic (agglomerates) and nanoscopic (exfoliation) levels. These results can be explained by a viscosity decrease related to the temperature increase, inducing reduced stresses and less energy transferred to the material. They are in agreement with previous findings of Modesti et al. (2005) and Lertwimolnun et Vergnes (2005).

\subsection{Overall influence of processing conditions on nanocomposite structure}

We have seen that screw speed, feed rate and barrel temperature have an important impact on the final structure of the nanocomposites. The dispersion quality was improved by increasing shear intensity and residence time. These statements were based on microscale and nanoscale quantitative analysis using $\mathrm{XRD}$, SEM and dynamic rheometry, as well as qualitative interpretation of TEM observations. Nevertheless, the optimisation of processing parameters would be facilitated if the nanocomposites structure could be linked to a single parameter. The specific mechanical energy (SME), introduced in section 2.2, quantifies the level of energy which is transferred to the material by mechanical input during extrusion. It takes both screw speed and feed rate values into account (see Eq. (1)) and was shown to be an adequate parameter for describing exfoliation by different authors (Lertwimolnun and Vergnes, 2007; Méderic et al., 
2009). Area ratio $A_{r}$ and melt yield stress $\sigma_{0}$ are plotted as a function of mesaured $S M E$ in Fig. 15 for all the processing conditions used (screw speed, feed rate and barrel temperature variations). The first important point to notice is that mastercurves were obtained for both $A_{r}$ and $\sigma_{0}$, which means that $S M E$ can be considered as a key parameter controlling the dispersion state. It can be seen in Fig. 15a that the area ratio decreases with the $S M E$ following a power law dependence. A similar relationship was recently found by Villmow et al. (2010) in the case of polycaprolactone/multiwall carbone nanotubes nanocomposites obtained by twin screw extrusion. As already mentioned in section 3.1, the melt yield stress grows linearly with SME until a value close to $600 \mathrm{kWh} / \mathrm{t}$. Above that critical $S M E$ value, $\sigma_{0}$ stabilizes at a plateau value, meaning that no more exfoliation seems to occur. Médéric et al. (2009) found a similar behaviour in the case of polyamide PA12/OMMT processed in an internal mixer, although the critical $S M E$ value was found to be much lower (around $140 \mathrm{kWh} / \mathrm{t}$ ), which means that this parameter might depend on the polymer-clay affinity (exfoliation is much easier in a polar PA12 matrix).

\subsection{Influence of nanocomposite structure on mechanical properties}

Apparent Young's moduli determined in uniaxial tensile tests are presented in Fig. 16 as function of screw speed and feed rate. Compared to the matrix value, we observe an increase between 20 and 50\%, depending on the processing condition. Enhanced mechanical properties are favoured by an increase in screw speed and a decrease in feed rate, which corresponds to an improvement of the clay dispersion. In all cases, in the tested conditions, no fragile rupture was observed, indicating that the engineering strain at break was only slightly modified in the nanocomposites. The impact of the micrometric dispersion (agglomerates) state on Young's modulus is shown in Fig. 17a: The apparent Young's modulus tends to increase when the area ratio decreases. It can be seen in Fig. 17b that the apparent Young's modulus increases also with the melt yield stress, indicating that an improved exfoliation leads to better mechanical 
properties. The best result corresponds to an increase of 50\% of the apparent Young's modulus, even though exfoliation is not total, as shown by TEM and XRD analyses. It means that the mechanical properties could probably further be improved by optimizing the exfoliation process. However in the case of polyamide/OMMT, where the exfoliation is close to $100 \%$, an increase in Young’s modulus up to 70\% was only reported (Fornes, 2003).

\section{Conclusions}

PP/PP-g-MA/OMMT nanocomposites with 5 wt\% OMMT and a fixed PP-g-MA/OMMT ratio of 2:1 were prepared by twin screw extrusion using a masterbatch dilution method. The influence of processing conditions on the nanocomposite structure (size of agglomerates, level of intercalation and exfoliation) was investigated over a wide range of screw speeds, feed rates and barrel temperatures. Morphological characterization of the samples was performed using SEM and TEM. Melt rheological analyses in the linear viscoelastic domain were carried out and the quality of OMMT exfoliation within the PP/PP-g-MA matrix was quantitatively characterized using the melt yield stress.

Both screw speed and feed rate were found to have an important effect on the nanocomposite structure, whereas the effect of barrel temperature was less pronounced in the investigated range. These effects can be seen as an influence of shear intensity and residence time on the dispersion mechanism during extrusion. XRD scans showed that characteristic peaks of the clay layered structure were still present, whatever the conditions, meaning that unexfoliated clay tactoids remained into the polymer matrix, which was confirmed by SEM and TEM observations. XRD also revealed that intercalation occurred during extrusion, even though the role of processing conditions on the intercalation process was not important, and despite probable intercalant degradation happened at high temperatures. The impact of processing parameters (screw speed, feed rate, barrel temperature) on the nanocomposite structure was 
described by a single processing parameter, the specific mechanical energy. Agglomerate dispersion was more effective when SME was increased. However exfoliation was clearly promoted by $S M E$ augmentation up to a critical value and then levelled off, whereas agglomerate dispersion was still going on. Structuration of nanocomposites using twin screw extrusion can thus be optimised by working under high SME conditions up to a critical limit beyond which exfoliation can no longer be enhanced. It was finally shown that mechanical properties (apparent Young's modulus) of the final nanocomposites are directly linked to the level of exfoliation resulting from processing conditions.

\section{Acknowledgements}

Authors thank Stephanie Bonny, Thierry Colin, Walid Bahloul, Nathalie Bozzolo and Gabriel Monge (CEMEF, France) for their precious contributions to this work, as well as Aleksey

Drozdov (DTI, Denmark) for gently providing the masterbatch. Financial support by the European Commission through FP7 project Nanotough-213436 is gratefully acknowledged. 


\section{References}

Cassagnau, P., “Melt rheology of organoclay and fumed silica nanocomposites”, Polymer, 49, 2183-2196 (2008).

Cho, J.W., Paul, D.R., “Nylon 6 nanocomposites by melt compounding”, Polymer, 42, 10831094 (2001).

Dennis, H.R., et al., "Effect of melt processing conditions on the extent of exfoliation in organoclay-based nanocomposites”, Polymer, 42, 9513-9522 (2001).

Fasulo, P.D., et al., “Extrusion processing of TPO nanocomposites ”, Polym. Eng. Sci., 44, 1036 (2004).

Fornes, T.D., et al., "Effect of organoclay structure on nylon 6 nanocomposite morphology and properties”, Polymer, 43, 5915-5933 (2002).

Fukushima, Y., Inagaki, S., "Synthesis of an intercalated compound of montmorillonite and 6polyamide”, J. Incl. Phenom., 5, 473-482 (1987).

Galgali, G., et al., “A rheological study on the kinetics of hybrid formation in polypropylene nanocomposites”, Macromol., 34, 852-858 (2001).

Giannelis, E.P., “Polymer layered silicate nanocomposites”, Adv. Mater., 8, 29-35 (1996).

Incarnato, L., et al., "Preparation and characterization of new melt compounded copolyamide nanocomposites”, Polymer, 44, 4625-4634 (2003).

Kato, M., et al., “Synthesis of polypropylene oligomer-clay intercalation compounds”, J. Appl. Polym. Sci., 66, 1781-1785 (1997).

Kim, D.H., et al., "Structure and properties of polypropylene-based nanocomposites: effect of PP-g-MA to organoclay ratio”, Polymer, 48, 5308-5323 (2007).

Krishnamoorti, R., Yurekli, K., "Rheology of polymer layered silicate nanocomposites ”, Curr. Opin. Colloid Interf. Sci., 6, 464-470 (2001). 
Lertwimolnun, W., Vergnes, B., "Influence of compatibilizer and processing conditions on the dispersion of nanoclay in a polypropylene matrix ”, Polymer, 46, 3462-3471 (2005).

Lertwimolnun, W., Vergnes, B., "Effect of processing conditions on the formation of polypropylene/organoclay nanocomposites in a twin screw extruder”, Polym. Eng. Sci., 46, 314-323 (2006).

Lertwimolnun, W., Vergnes, B., "Influence of screw profile and extrusion conditions on the microstructure of polypropylene/organoclay nanocomposites”, Polym. Eng. Sci., 47, 2100-2109 (2007).

Li, J., et al., "Study on kinetics of polymer melt intercalation by a rheological approach”, J. Appl. Polym. Sci., 89, 318-323 (2003).

Médéric, P., et al., "Influence of melt-blending conditions on structural, rheological, and interfacial properties of polyamide-12 layered silicate nanocomposites”, Polym. Eng. Sci., 46, 986-994 (2006).

Médéric, P., et al., "Structural and rheological properties as a function of mixing energy for polymer/layered silicate nanocomposites”, Intern. Polym. Proc., 24, 261-266 (2009).

Mobuchon, C., et al., "Effect of flow history on the structure of a non-polar polymer/clay nanocomposite model system”, Rheol. Acta, 46, 1045-1056 (2007).

Modesti, M., et al., "Effect of processing conditions on morphology and mechanical properties of compatibilized polypropylene nanocomposites”, Polymer, 46,10237-10245 (2005).

Modesti, M., et al., “Thermal behaviour of compatibilised polypropylene nanocomposite: Effect of processing conditions”, Polym. Deg. Stab., 91, 672-680 (2006).

Okada, A., Usuki, A., “The chemistry of polymer-clay hybrids”, Mater. Sci. Eng., 3, 109-115 (1995). 
Peltola, P., et al., "Effect of rotational speed of twin screw extruder on the microstructure and rheological and mechanical properties of nanoclay-reinforced polypropylene nanocomposites”, Polym. Eng. Sci., 46, 995-1000 (2006).

Pignon, F., et al., “Thixotropic behavior of clay dispersions: Combinations of scattering and rheometric techniques”, J. Rheol., 42, 1349-1373 (1998).

Poulesquen, A., Vergnes, B., “A study of residence time distribution in co-rotating twin screw extruders; Part I: theoretical modelling”, Polym. Eng. Sci., 43, 1841-1848 (2003).

Ren, J., et al., "Disorientation kinetics of aligned polymer layered silicate nanocomposite”, Macromol., 36, 4188-4194 (2003).

Shah, R.K., Paul, D.R., "Nylon 6 nanocomposites prepared by a melt mixing masterbatch process”, Polymer, 45, 2991-3000 (2004).

Solomon, M.J., et al., “Rheology of polypropylene/clay hybrid materials”, Macromol., 34, 18641872 (2001).

Toorman, E.A., “Modelling the thixotropic behaviour of dense cohesive sediment suspensions”, Rheol. Acta, 36, 56-65 (1997).

Treece, M.A., Oberhauser, J.P., “Soft glassy dynamics in polypropylene-clay nanocomposites”, Macromol., 40, 571-582 (2007).

Usuki, A., et al., “Synthesis of nylon 6-clay hybrid”, J. Mater. Res., 8, 1179- 1184 (1993).

Vaia, R.A., et al., "Synthesis and properties of two-dimensional nanostructures by direct intercalation of polymer melts in layered silicates”, Chem. Mater., 5, 1694-1696 (1993).

Vaia, R.A., et al., “Kinetics of polymer melt intercalation”, Macromol., 28, 8080-8085 (1995).

Vergnes, B., "The use of apparent yield stress to characterize exfoliation in polymer nanocomposites ”, Intern. Polym. Proc., 26, 229-232 (2011).

Vergnes, B., Lertwimolnun, W., “Chapter 3: Impact of Processing Conditions on the Morphology, Structure and Properties of Polymer-Organoclay Nanocomposites”, in 
Polymer Nanocomposite Research Advances, Sabu, T., Gennady Z. (Eds.), Nova Science Publishers, New York, p. 49-93 (2008).

Villmow, T., et al., "Influence of screw configuration, residence time, and specific mechanical energy in twin-screw extrusion of polycaprolactone/multi-walled carbon nanotube composites”, Compos. Sci. Technol., 70, 2045-2055 (2010).

Zouari, R., et al., "Time-evolution of the structure of organoclay/polypropylene nanocomposites and application of the time/temperature superposition principle”, submitted to J. Rheol. (2011). 


\section{Figure captions}

Fig. 1. Screw profile used in the experiments

Fig. 2. SEM micrographs of Dellite ${ }^{\circledR} 67 G$ powder captured with secondary electron detector at different magnifications, (a) x 1000, (b) x 5000

Fig. 3. SEM micrographs (x 200) of the nanocomposites for various screw speed values: (a) 100 rpm, (b) $300 \mathrm{rpm}$, (c) $500 \mathrm{rpm}$, (d) $700 \mathrm{rpm}$, (e) $900 \mathrm{rpm}\left(T_{b}=180^{\circ} \mathrm{C}, Q=3 \mathrm{~kg} / \mathrm{h}\right)$. Clay agglomerates within the PP/PP-g-MA matrix are evidenced as black objects.

Fig. 4. Dependence of area ratio $A_{r}$ and agglomerate surface density $N_{s}$ with screw speed $\left(T_{b}=\right.$ $\left.180^{\circ} \mathrm{C}, Q=3 \mathrm{~kg} / \mathrm{h}\right)$.

Fig. 5. Bright field TEM micrographs at x 11500 and x 88000 magnifications for various screw speed values: (a,b) $100 \mathrm{rpm}$, (c,d) $500 \mathrm{rpm}$, (e,f) $900 \mathrm{rpm}\left(T_{b}=180^{\circ} \mathrm{C}, Q=3 \mathrm{~kg} / \mathrm{h}\right)$.

Fig. 6. Storage modulus as function of strain at fixed angular frequency ( $\omega \square=1 \mathrm{rad} / \mathrm{s}$ ) for nanocomposites processed at various screw speeds $\left(T_{b}=180^{\circ} \mathrm{C}, Q=3 \mathrm{~kg} / \mathrm{h}\right)$.

Fig. 7. Frequency sweep analysis: (a) storage modulus and (b) complex viscosity as function of pulsation for nanocomposites processed at various screw speeds $\left(T_{b}=180^{\circ} \mathrm{C}, Q=3\right.$ $\mathrm{kg} / \mathrm{h})$.

Fig. 8. Melt yield stress as function of screw speed $\left(T_{b}=180^{\circ} \mathrm{C}, Q=3 \mathrm{~kg} / \mathrm{h}\right)$.

Fig. 9. SEM micrographs (x 200) of clay agglomerates within PP/PP-g-MA matrix for various feed rate values: (a) $3 \mathrm{~kg} / \mathrm{h}$, (b) $6 \mathrm{~kg} / \mathrm{h}$, (c) $10 \mathrm{~kg} / \mathrm{h}$, (d) $15 \mathrm{~kg} / \mathrm{h}$, (e) $20 \mathrm{~kg} / \mathrm{h}\left(T_{b}=180^{\circ} \mathrm{C}\right.$, $N=500 \mathrm{rpm})$.

Fig. 10. Dependence of area ratio $A_{r}$ and agglomerate surface density $N_{s}$ with feed rate $\left(T_{b}=\right.$ $\left.180^{\circ} \mathrm{C}, N=500 \mathrm{rpm}\right)$ 
Fig. 11. Bright field TEM micrographs at x 11500 and x 88000 magnifications for various feed rate values: (a,b) $3 \mathrm{~kg} / \mathrm{h}$, (c,d) $10 \mathrm{~kg} / \mathrm{h},(\mathrm{e}, \mathrm{f}) 20 \mathrm{~kg} / \mathrm{h}\left(T_{b}=180^{\circ} \mathrm{C}, N=500 \mathrm{rpm}\right)$.

Fig. 12. Complex viscosity as function of pulsation for nanocomposites processed at various feed rates $\left(T_{b}=180^{\circ} \mathrm{C}, N=500 \mathrm{rpm}\right)$.

Fig. 13. Melt yield stress as function of feed rate $\left(T_{b}=180^{\circ} \mathrm{C}, N=500 \mathrm{rpm}\right)$.

Fig. 14. Melt yield stress as function of barrel temperature ( $N=500 \mathrm{rpm}, Q=3 \mathrm{~kg} / \mathrm{h})$.

Fig. 15. Mastercurves obtained for screw speed, feed rate and barrel temperature variations: (a) area ratio and (b) melt yield stress as function of SME.

Fig. 16. Apparent Young's modulus as function of (a) screw speed, (b) feed rate $\left(T_{b}=180^{\circ} \mathrm{C}\right)$.

Fig. 17. Apparent Young's modulus as function of (a) area ratio, (b) melt yield stress for all tested conditions. 


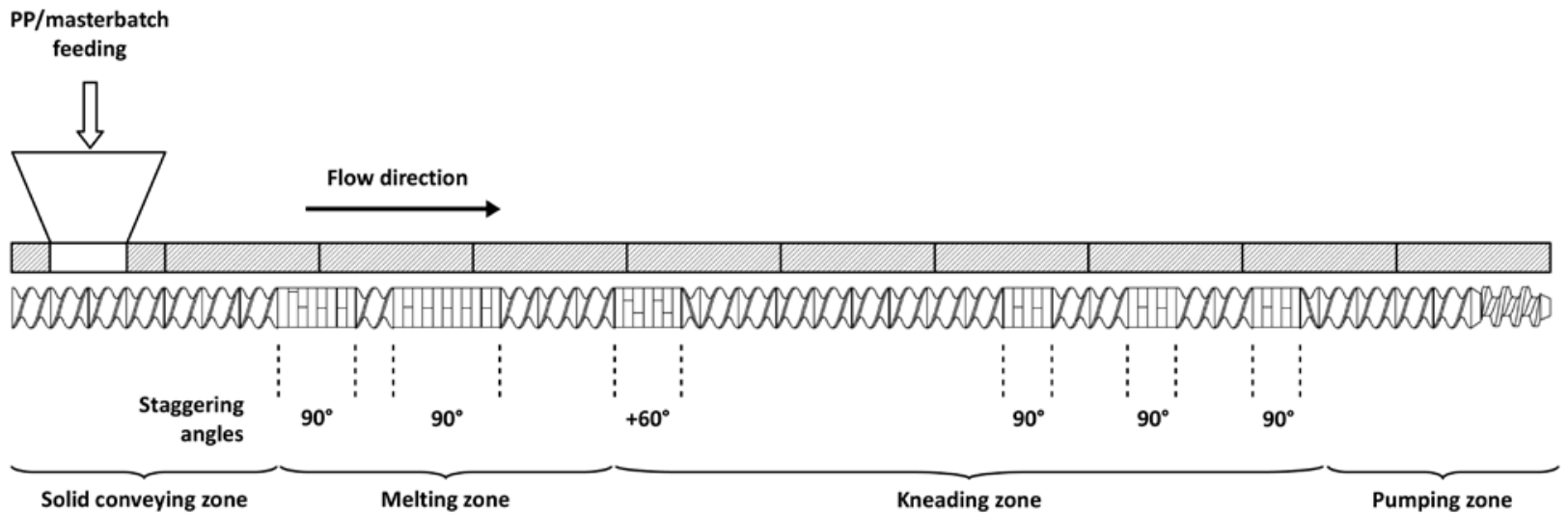

Fig. 1. Domenech et al. 

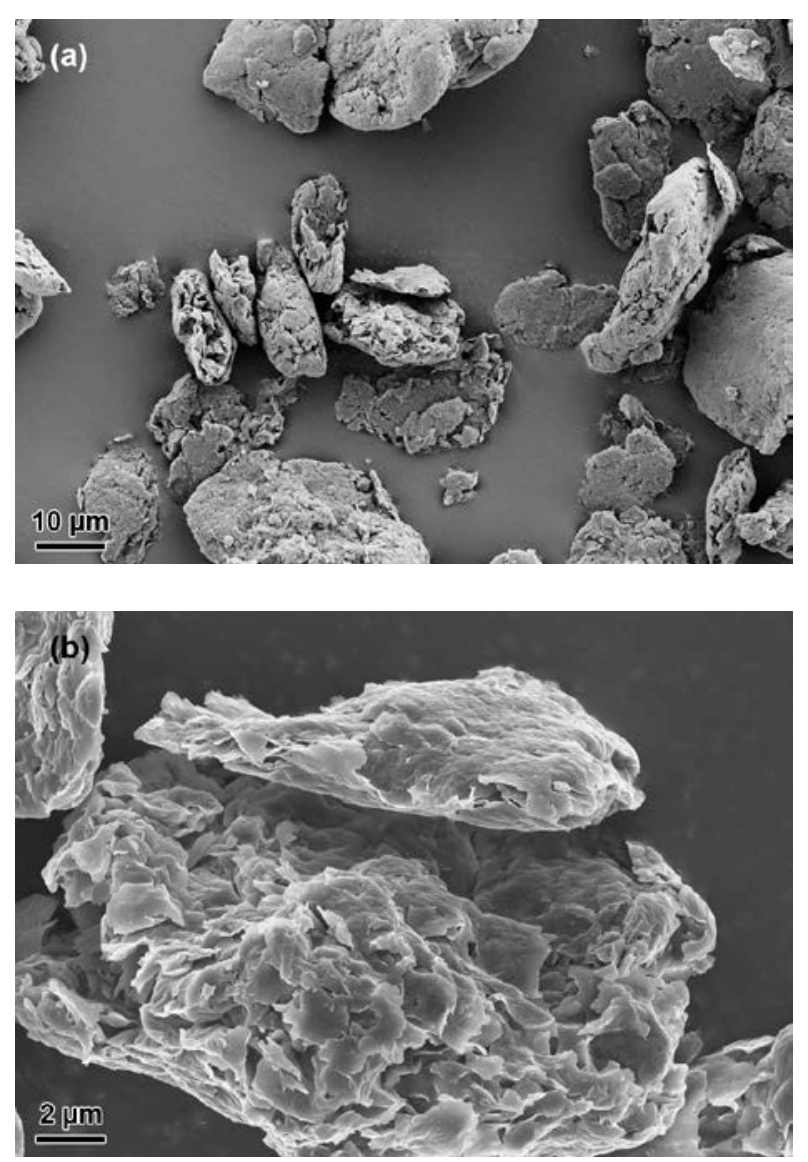

Fig. 2. Domenech et al. 


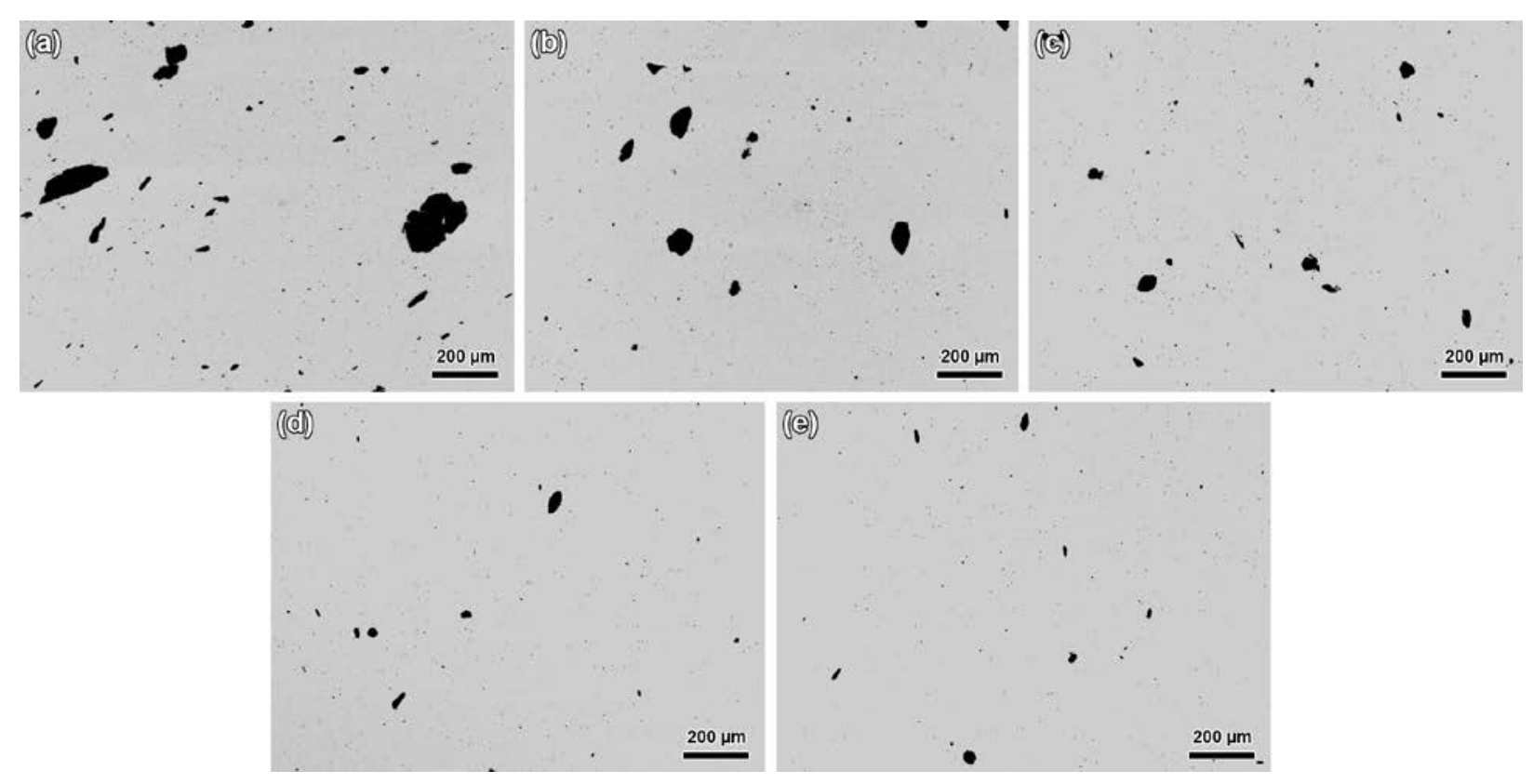

Fig. 3. Domenech et al. 


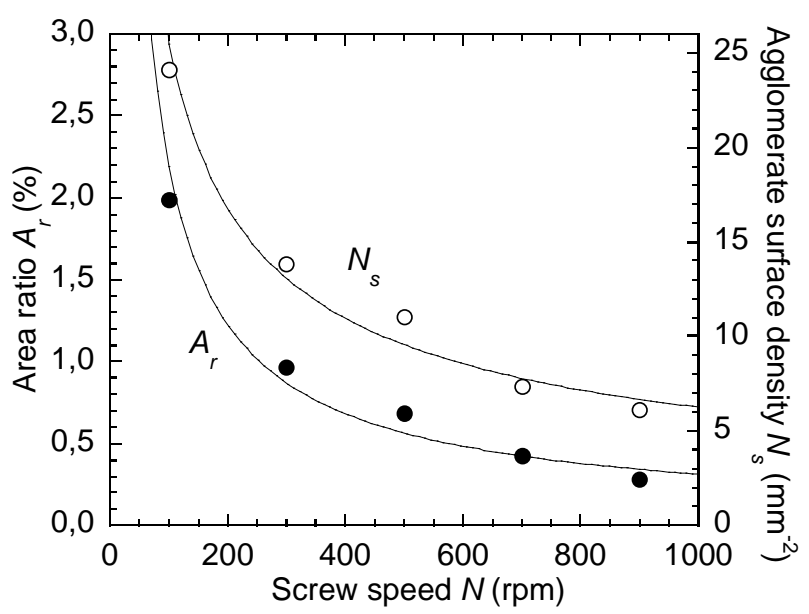

Fig. 4. Domenech et al. 

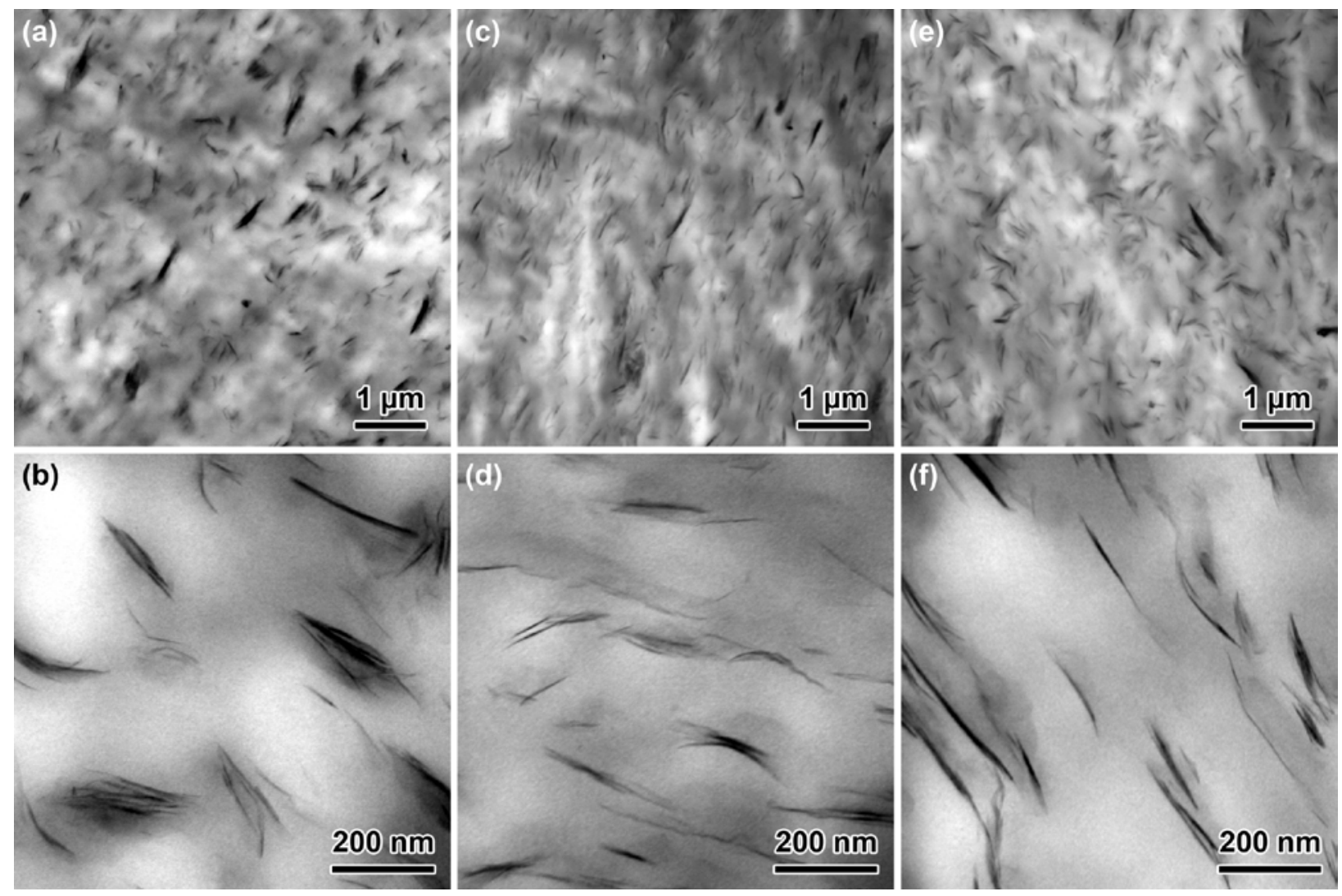

Fig. 5. Domenech et al. 


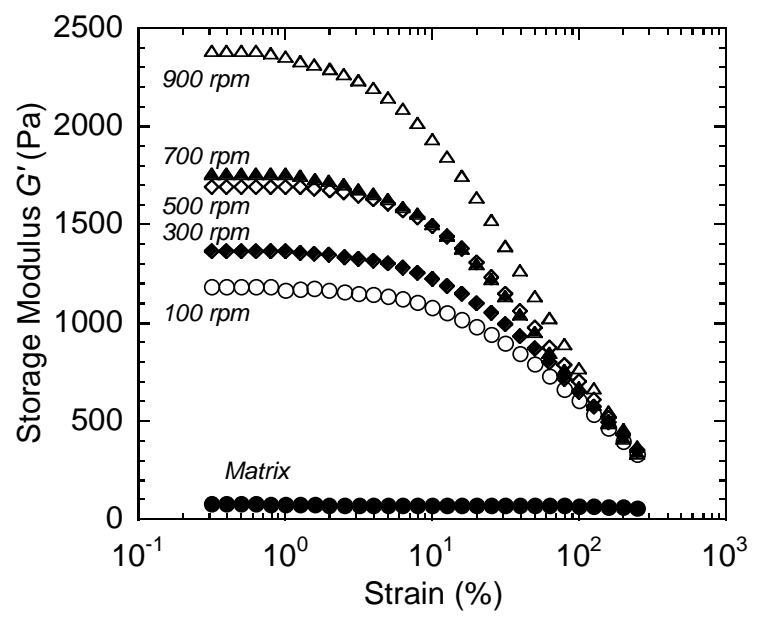

Fig. 6. Domenech et al. 

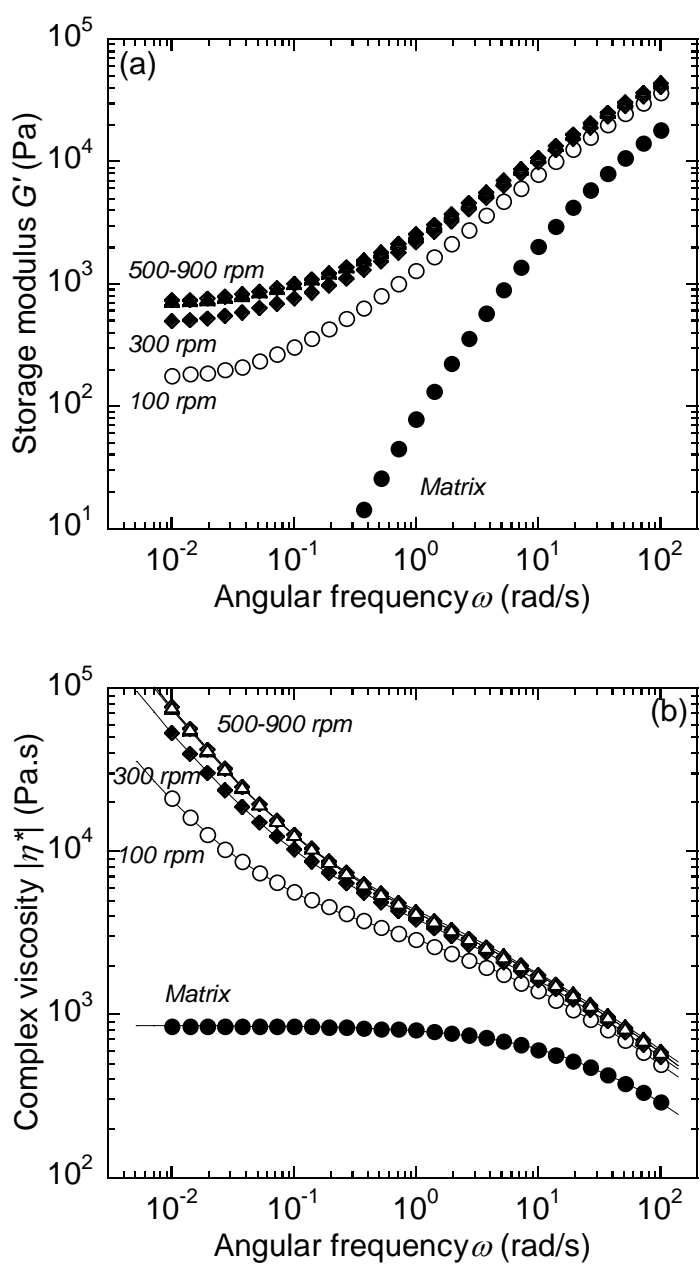

Fig. 7. Domenech et al. 


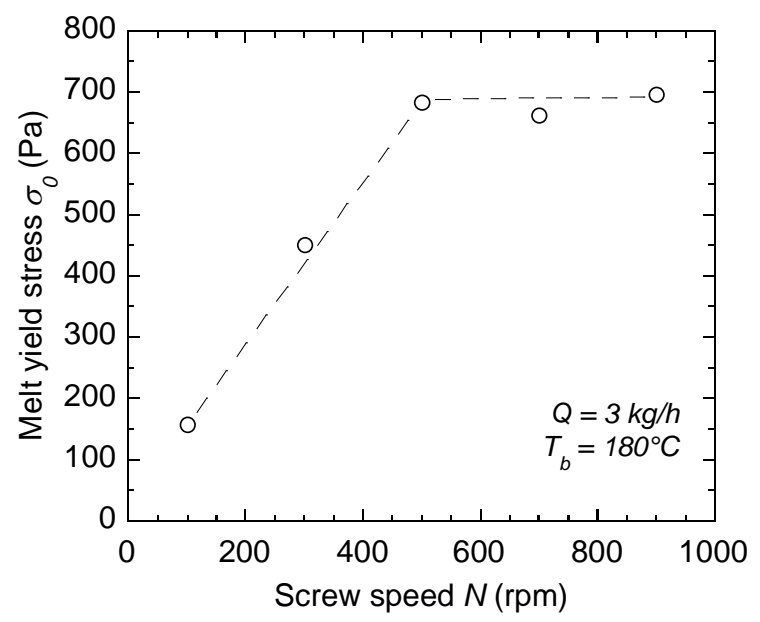

Fig. 8. Domenech et al. 


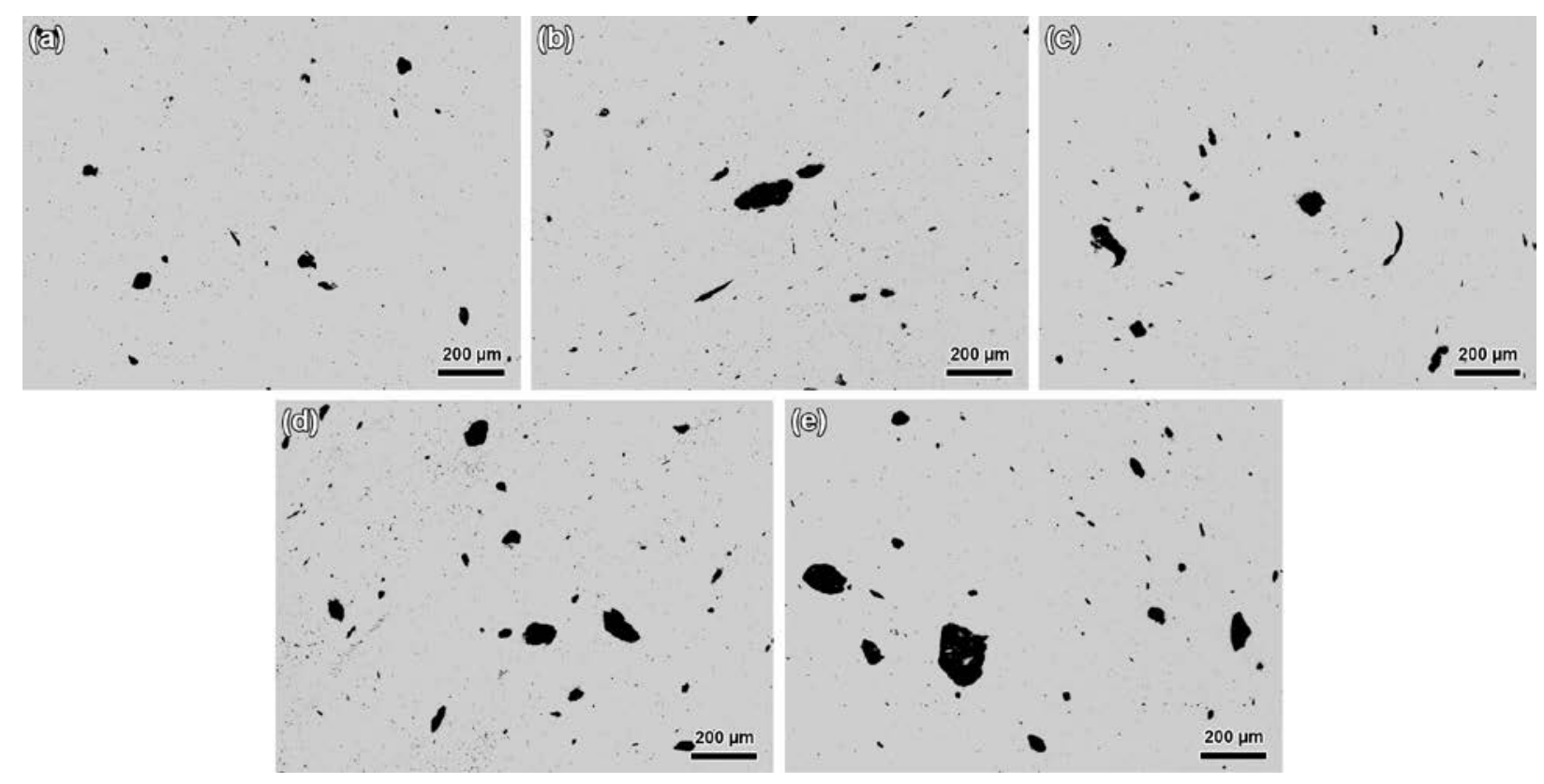

Fig. 9. Domenech et al. 


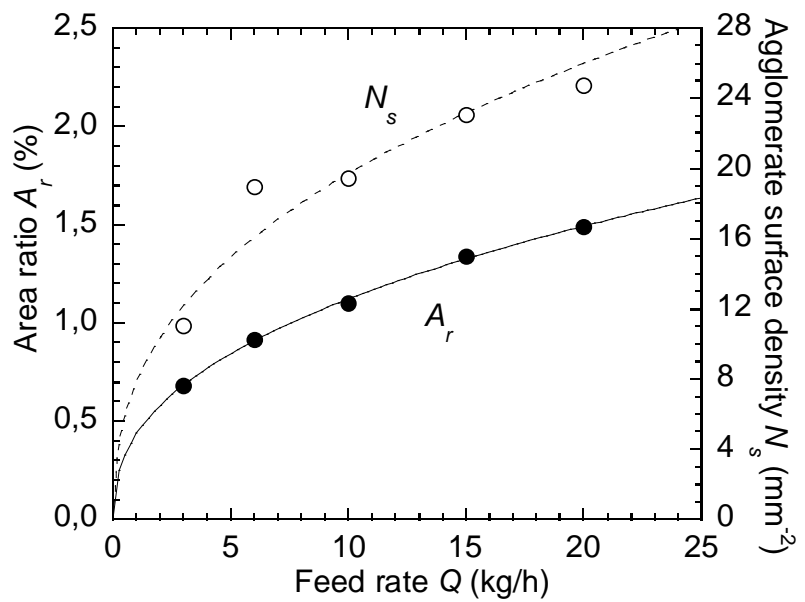

Fig. 10. Domenech et al. 

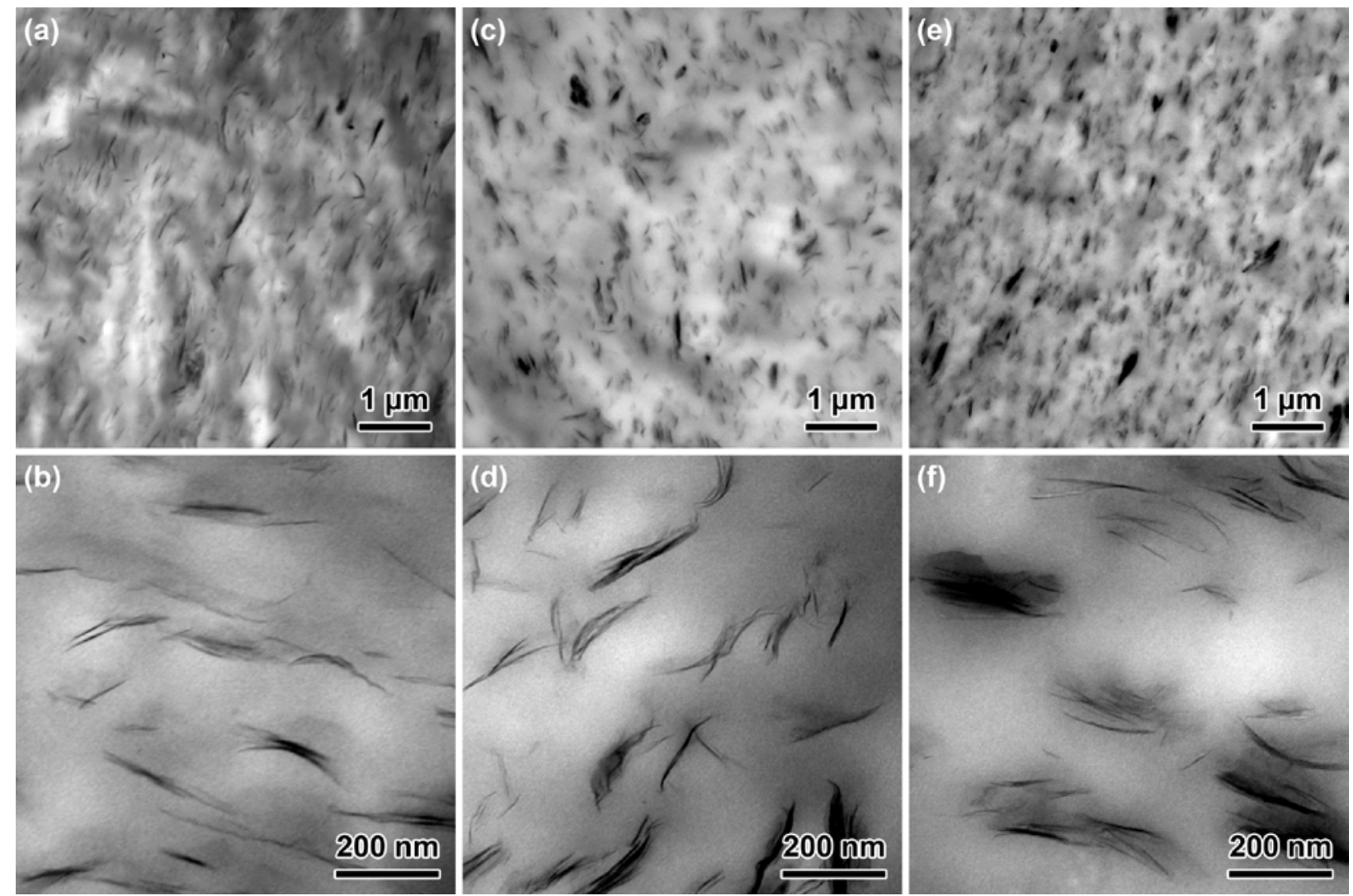

Fig. 11. Domenech et al. 


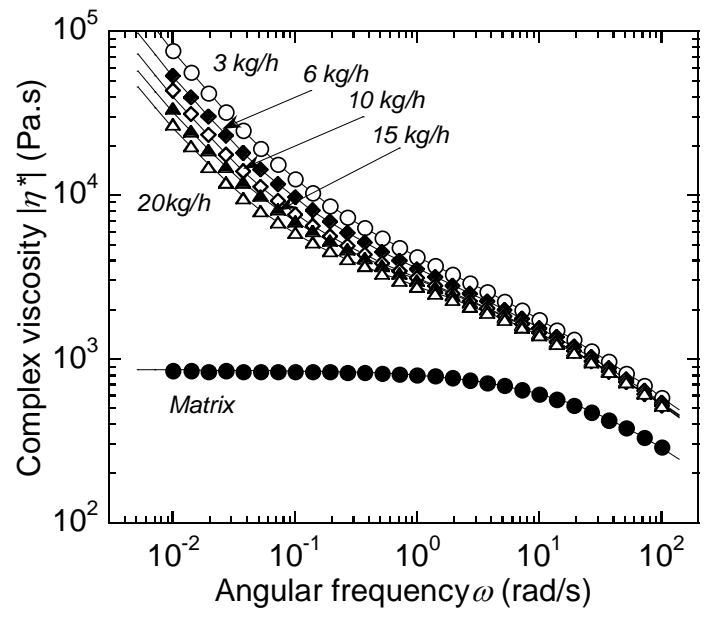

Fig. 12. Domenech et al. 


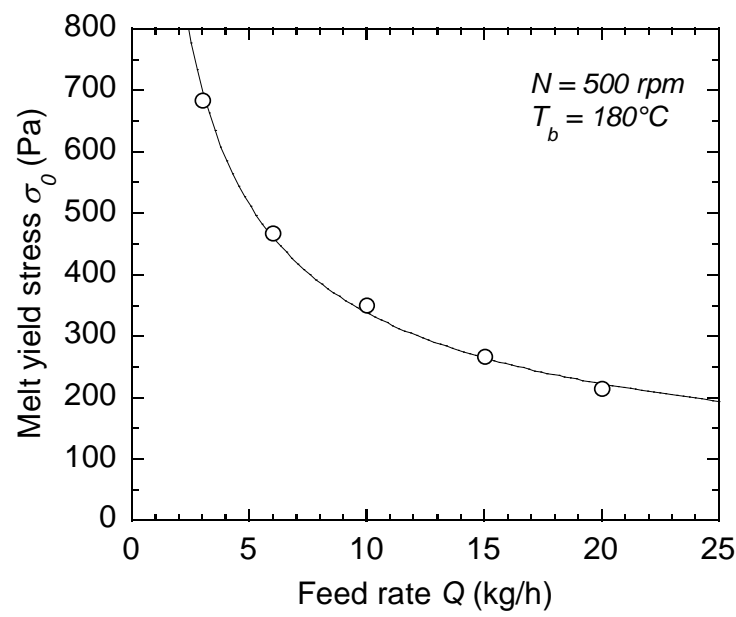

Fig. 13. Domenech et al. 


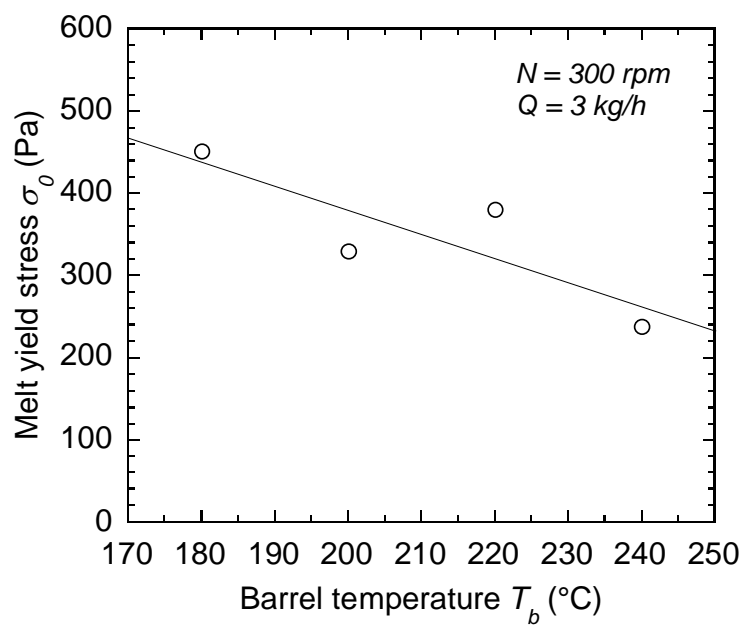

Fig. 14. Domenech et al. 

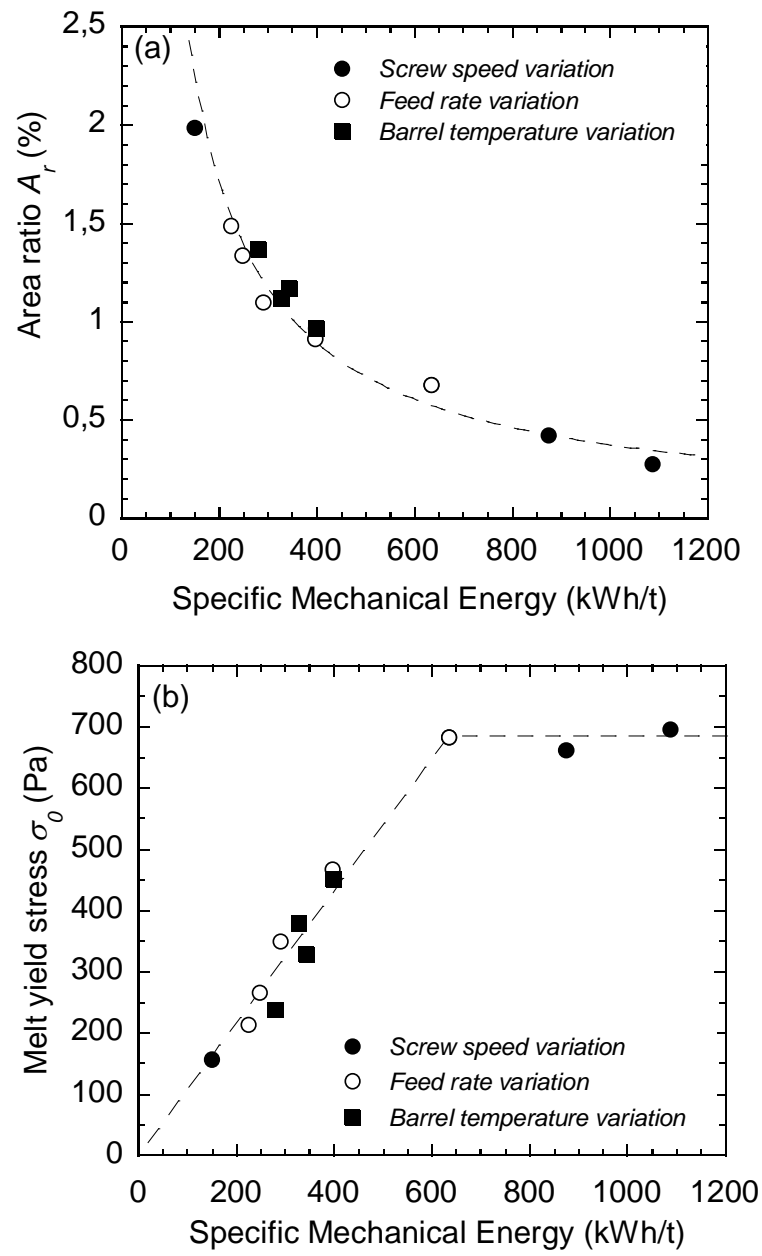

Fig. 15. Domenech et al. 

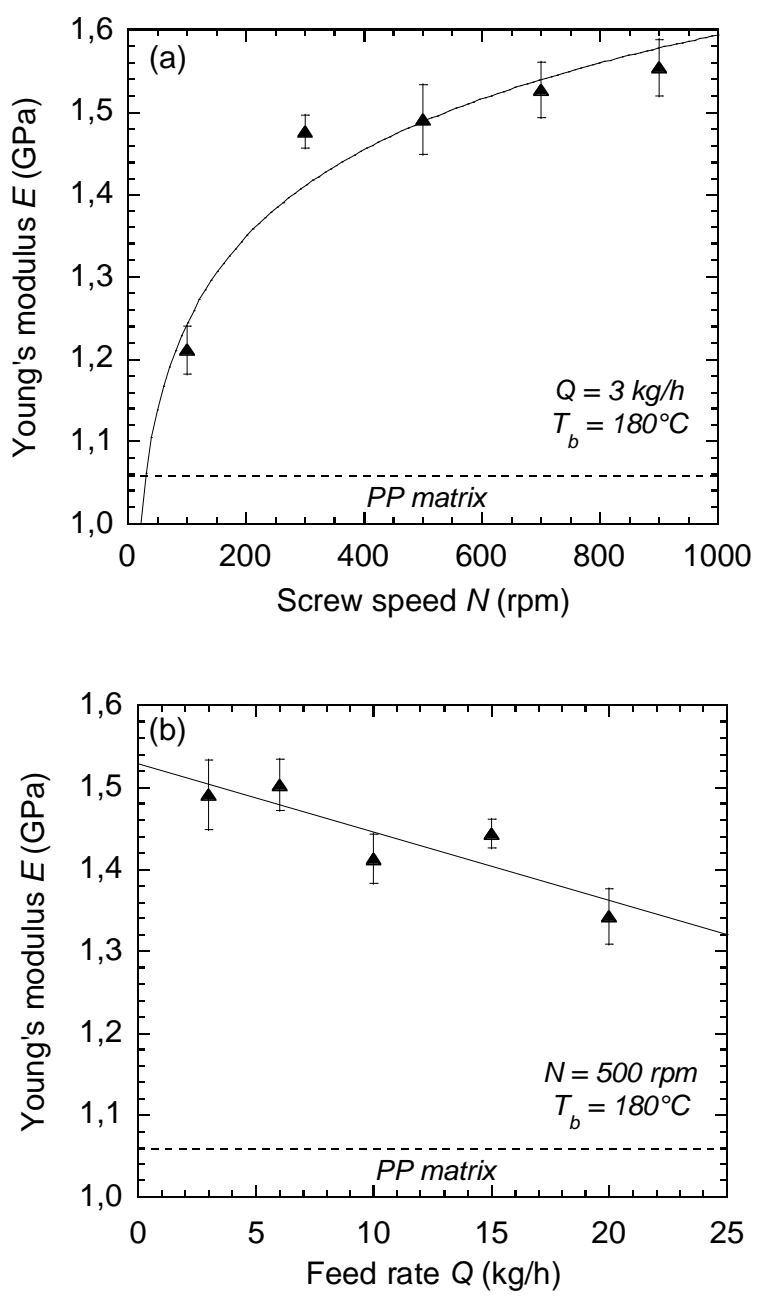

Fig. 16. Domenech et al. 

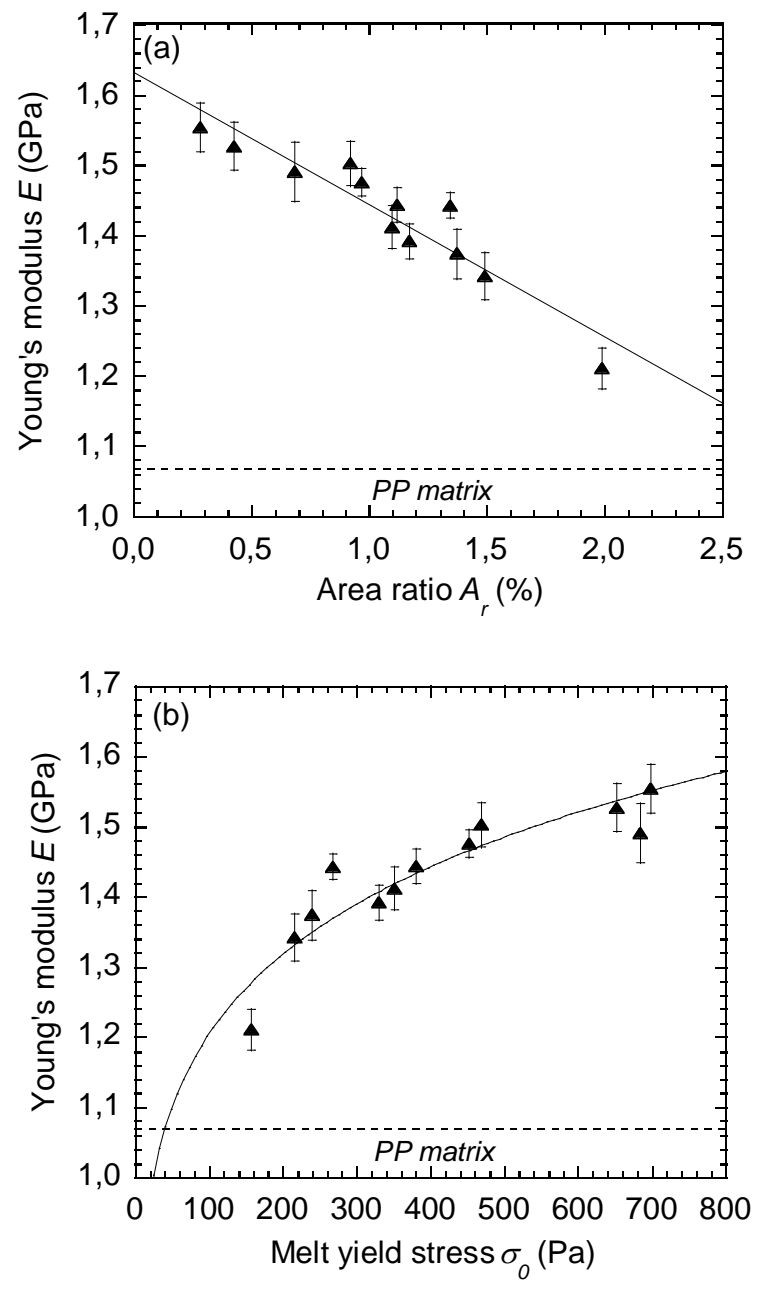

Fig. 17. Domenech et al. 